\title{
ANALISA MESIN PENDINGIN ADSORPSI DENGAN MENGGUNAKAN TENAGA MATAHARI
}

\author{
M. Darwis Rambe ${ }^{1}$, Tulus B. Sitorus ${ }^{2}$, Himsar Ambarita ${ }^{3}$, Farel H. Napitupulu ${ }^{4}$, Andianto P. ${ }^{5}$ \\ 1.2,3,4,5 Departemen Teknik Mesin, Fakultas Teknik, Universitas Sumatera Utara \\ E-mail : ndarray72@yahoo.com
}

\begin{abstract}
ABSTRAK
Penggunaan energi besar - besaran saat ini telah membuat membuat manusia mengalami krisis energi. Untuk mengatasi krisis energi di masa depan beberapa alternatif sumber energi mulai dikembangkan, salah satunya ialah energi matahari. Energi matahari biasa digunakan sebagai penerang dan sumber panas bagi kehidupan sehari - hari namun ternyata energi matahari dapat dikembangkan menjadi sumber energi lainnya misalnya untuk pendingin. Mesin pendingin siklus adsorpsi ini digerakkan oleh tenaga matahari dan tidak menggunakan energi mekanik sama sekali. Mesin pendingin siklus adsorpsi memiliki 3 komponen utama yaitu kolektor, kondensor, dan evaporator. Ketiga komponen utama alat ini terbuat dari bahan stainless steel yang bertujuan agar tahan terhadap korosi akibat dari refrigeran yang digunakan. Tujuan dari peneltian ini untuk mengetahui temperatur maksimum pada kolektor dan temperatur minimum pada air yang di dinginkan dan mengetahui laju perpindahan panas dari kolektor, kondensor, dan evaporator. Prosedur pengujian dengan memanaskan kolektor surya (desorpsi) dari pukul 08.00 WIB - 17.00 WIB, sedangkan proses pendinginan alamiah (adsorpsi) berlangsung dari pukul 17.00 WIB - 08.00 WIB. Pada penelitian ini menggunakan pasangan Alumina aktif moleculer seave $13 \mathrm{X}$ sebagai adsorben sebanyak $7 \mathrm{Kg}$ dan methanol sebagai refrigerant sebanyak $4 \mathrm{~L}$. Dari hasil pengujian dan perhitungan yang telah dilakukan didapat bahwa temperatur maksimum pada kolektor $102{ }^{\circ} \mathrm{C}$ dan temperatur minimum air $18,40{ }^{\circ} \mathrm{C}$. Efisiensi kolektor tertinggi pada hasil pembahasan adalah $52 \%$.
\end{abstract}

Kata kunci: Kolektor, kondensor, evaporator, adsorpsi, desorpsi

\section{PENDAHULUAN}

Penggunaan energi besar - besaran saat ini telah membuat manusia mengalami krisis energi, ini di sebabkan ketergantungan terhadap bahan bakar fosil seperti minyak dan gas alam sangat tinggi. Sebagaimana yang kita ketahui, bahan bakar fosil merupakan sumber daya alam yang tidak dapat kita perbarui dan akan habis suatu saat. Untuk mengatasi krisis energi masa depan beberapa alternatif sumber energi mulai dikembangkan, salah satunya ialah energi matahari, energi matahari biasa digunakan sebagai penerang dan sumber panas bagi kehidupan sehari - hari namun ternyata energi matahari dapat dikembangkan menjadi sumber energi lainnya.

Seperti diketahui bahwa energi surya dapat dimanfaatkan sebagai sumber energi panas dan sebagai sumber energi listrik. Salah satu aplikasi dari pemanfaatan energi termal matahari adalah mesin pendingin siklus adsorpsi. Mesin ini digerakkan oleh tenaga matahari dan tidak menggunakan energi mekanik sama sekali. Dengan karakteristik iklim cuaca kota Medan, sangat diperlukan pendinginan yang umumnya digunakan untuk pengkondisian udara. Keunggulan utama siklus ini adalah temperatur regenerasi yang relatif rendah sehingga cocok untuk aplikasi energi surya dan tidak memiliki bagian yang berputar karena semua gerakan fluida memanfaatkan efek alamiah. 
Keunggulan dari mesin pendingin siklus adsorpsi ini adalah temperatur regenerasi yang relatif rendah sehingga cocok untuk aplikasi energi surya dan tidak memiliki bagian yang berputar karena semua gerakan fluida memanfaatkan efek alamiah. [1]

\section{TINJAUAN PUSTAKA}

\section{Siklus Adsorpsi}

Adsorpsi adalah suatu proses yang terjadi ketika suatu fluida (cairan maupun gas) terikat pada suatu padatan (zat penyerap, adsorben) dan akhirnya membentuk suatu lapisan tipis atau film (zat terserap: adsorbat) pada permukaannya. Berbeda dengan absorpsi yang merupakan penyerapan fluida oleh fluida lainnya dengan membentuk suatu larutan.

Adsorpsi dibedakan menjadi dua jenis, yaitu adsorpsi fisika yang disebabkan oleh gaya Van Der dan secara kimia (terjadi reaksi antara zat yang diserap dengan adsorben).

Apabila daya tarik menarik antara zat terlarut dengan adsorben besar maka zat yang terlarut akan diadsorpsi pada permukaan adsorben. Inilah yang disebut dengan gaya Van Der Waals. Pada proses ini gaya yang menahan molekul fluida pada permukaan solid relatif lemah, dan besarnya sama dengan gaya kohesi molekul pada fase cair (gaya Van Der Waals) mempunyai derajat yang sama dengan panas kondensasi dari gas menjadi cair. Keseimbangan antara permukaan solid dengan molekul fluida biasanya cepat tercapai dan bersifat reversibel[2].

\section{Adsorben}

Alumina Aktif

Alumina aktif dibuat dari aluminium hidroksida dengan dehydroxylating dengan cara yang menghasilkan bahan yang sangat berpori, bahan ini dapat memiliki luas permukaan signifikan lebih dari 200 meter persegi / g. Senyawa ini digunakan sebagai pengering dan sebagai filter fluoride, arsenik dan selenium dalam air minum. Alumina aktif terbuat dari aluminium oksida (alumina, Al2O3), substansi kimia yang sama seperti safir dan ruby. Ini memiliki luas permukaan yang sangat tinggi untuk rasio berat, karena banyak "terowongan seperti" pori-pori[3].

\section{Metanol}

Metanol juga dikenal sebagai metil alkohol, wood alcohol atau spiritus. Metanol merupakan bentuk alkohol paling sederhana. Pada keadaan atmosfer, metanol berbentuk cairan yang ringan, mudah menguap, tidak berwarna, mudah terbakar dan beracun dengan bau yang khas (berbau lebih ringan dari pada etanol). Metanol digunakan sebagai bahan pendingin anti beku, pelarut, bahan bakar dan sebagai bahan aditif bagi etanol industri[4].

\section{Keamanan Refrigeran}

Refrigeran dirancang untuk digunakan pada ruangan tertutup atau tidak bercampur dengan udara luar. Jika ada kebocoran karena sesuatu hal yang tidak diinginkan, maka refrigeran ini akan keluar sistem dan bisa saja terhirup oleh manusia. Untuk menghindari halhal yang tidak diinginkan maka refrigeran harus dikategorikan aman atau tidak aman. Ada dua faktor yang digunakan untuk mengklasifikasikan refrigeran berdasarkan keamanan, yaitu bersifat racun dan mudah terbakar.

\section{Kalor (Q)}

Kalor adalah salah satu bentuk energi yang dapat mengakibatkan perubahan suhu[6]. 


\section{a.Kalor Laten}

Energi yang diperlukan disebut kalor transformasi. Kalor yang diperlukan untuk merubah fasa dari bahan bermassa $\mathrm{m}$ adalah

$$
Q_{L}=L_{e} m
$$

Dimana :

$Q_{L}=$ Kalor laten $(\mathrm{J})$

$L e=$ Kapasitas kalor spesifik laten $(\mathrm{J} / \mathrm{kg})$

$M=$ Massa zat $(\mathrm{kg})$

b. Kalor Sensibel

kalor sensibel adalah kalor yang diberikan atau yang dilepaskan oleh suatu jenis fluida sehingga temperaturnya naik atau turun tanpa menyebabkan perubahan fasa fluida tersebut.

$Q_{s}=m C_{p} \Delta T$

Dimana:

$Q_{s} \quad=$ Kalor sensible $(J)$

$C_{p} \quad=$ Kapasitas kalor spesifik sensibel (J/kg.K)

$\Delta T \quad=$ Beda temperatur $(\mathrm{K})$

\section{Perpindahan Panas}

Mekanisme perpindahan panas yang terjadi dapat dikategorikan atas 3 jenis yaitu: konduksi, konveksi dan radiasi.

\section{-Konduksi}

Secara matematik, untuk plat datar seperti gambar di atas ini, laju perpindahan panas konduksi dirumuskan dengan persamaan:

$$
Q_{c}=k A \frac{\Delta T}{\Delta x}
$$

Atau sering dirumuskan dengan persamaan berikut ini.

Dimana:

$$
Q_{c}=k A \frac{d T}{d x}
$$

$Q_{c} \quad=$ Laju aliran energi (W)

A $\quad=$ Luas penampang $\left(\mathrm{m}^{2}\right)$

$\Delta \mathrm{T}=$ Beda temperatur $(\mathrm{K})$

$\Delta x \quad=$ Panjang $(\mathrm{m})$

$\mathrm{k}=$ Daya hantar (konduktivitas) (W/m.K)

\section{- Konveksi}

Secara matematik perpindahan panas konveksi pada permukaan pelat rata dapat dirumuskan dengan persamaan berikut ini.

Dimana:

$$
Q_{h}=h A\left(T_{s}-T_{L}\right)
$$

$Q_{h} \quad=$ Laju perpindahan panas konveksi (W)

$h \quad=$ Koefisien konveksi $\left(\mathrm{W} / \mathrm{m}^{2} \mathrm{~K}\right)$

$A=$ Lluas penampang perpidahan panas $\left(\mathrm{m}^{2}\right)$

$T_{s} \quad=$ Temperatur permukaan

$T_{L} \quad=$ Temperatur fluida

-Radiasi

Persamaan yang dapat digunakan untuk menghitung laju perpindahan panas radiasi antara permukaan pelat dan lingkungannya adalah: 


\section{Dimana}

$$
Q_{r}=e \sigma A T^{4}
$$

$Q_{r} \quad=$ Laju perpindahan panas radiasi (W)

$\sigma=$ Konstanta Boltzman: $5,67 \times 10^{-8} \mathrm{~W} / \mathrm{m}^{2} \mathrm{~K}^{4}$

e $\quad=$ Emisivitas $(0 \leq \mathrm{e} \leq 1)$

$\mathrm{T}=$ Temperatur $(\mathrm{K})$

\section{METODOLOGI PENELITIAN}

\section{Tempat dan Waktu}

Tempat penelitian adalah laboratorium Teknik Pendingin, gedung Fakultas Teknik USU. Waktu pelaksanaan penelitian \pm 5 bulan.

\section{Bahan}

Pada penelitian ini, bahan pengujian yang digunakan adalah sebagai berikut.

1. Alumina aktif

Adsorben yang digunakan pada penelitian ini adalah alumina aktif sebanyak $7 \mathrm{Kg}$.

2. Refrigeran

Untuk terjadinya suatu proses pendinginan diperlukan suatu bahan yang mudah dirubah bentuknya dari gas menjadi cair atau sebaliknya. Refrigeran yang digunakan pada pengujian ini adalah:

- Metanol dengan kadar kemurnian 99\% sebanyak 4 liter

\section{Alat Ukur yang Digunakan}

Alat-alat ukur yang digunakan pada pengujian mesin pendingin adsorpsi dengan menggunakan tenaga matahari ini adalah Manometer Vakum, Agilent, dan HOBO.

\section{Peralatan yang Digunakan}

Pompa Vakum, Katup, Pipa Penghubung, Selang Karet, Kotak Isolasi gelas ukur.

\section{Prosedur Pengujian}

Prosedur pengujian dapat diuraikan sebagai berikut ini.

1. Proses assembling/ penyambungan komponen mesin pendingin tenaga surya. Komponen dari mesin kolektor, kondensor, dan evaporator dihubungkan / dirangkai. Bagian yang mengalami sambungan yaitu antar pipa dan selang karet di lem dengan baik agar tidak rerjadi kebocoran.

2. Kemudian apabila komponen mesin pendingin di rangkai / dihubungkan. Maka, pemasangan thermokopel dilakukan. Sebelum pemasangan sebaiknya kabel thermokopel dicek di setiap titiknya apakah terjadi eror atau tidak. Apabila kabel sudah dalam keadaan baik, maka pemasangan pun dilakukan di setiap titik yang telah ditentukan.

3. Setelah titik thermokopel selesai dipasang. Maka penelitian pun dilakukan dengan penjemuran adsorber di bawah sinar matahari. Penjemuran ini dilakukan di lantai 4 gedung Magister Teknik Mesin. Proses desorpsi berlangsung \pm 9 jam dari pukul 08.00 WIB - 17.00 WIB.

4. Setelah proses desorpsi berakhir, maka pemvakuman dilakukan. Tujuannya adalah untuk mengeluarkan partikel-partikel kotoran dari adsorben baik itu gas dan air. Proses pemvakuman dilakukan \pm 20 menit. 
5. Kemudian metanol diisi pada evaporator dan katup evaporator ditutup setelah itu, kemudian semua sambungan dihubungkan. Kemudian dilakukan pemvakuman kembali dari katup pembuangan untuk mengosongkan udara yang ada pada pipa-pipa setelah itu katup evaporator dibuka secara pelan. Setelah metanol kelihatan mendidih, pemvakuman dihentikan dan katup buang pun ditutup.

6. Proses adsorpsi terjadi pada malam hari , temperatur pada proses adsorpsi turun seiring dengan turunnya temperatur lingkungan. Pada malam hari dengan turunnya temperatur adsorpsi, maka alumina akan menyerap metanol sehingga metanol akan menguap pada evaporator dan naik ke adsorben. Dengan penguapan metanol ini maka temperatur evaporator pun akan turun yang mengakibatkan temperatur air yang ada di sekitarnya juga akan turun. Pengukuran tekanan dilakukan setiap satu jam sekali.

7. Proses desorpsi terjadi pada siang hari, dan kaca kolektor dipasang dan diisolsi dengan sempurna sehingga tidak ada udara yang mengalir masuk dan keluar dari adsorber. Kotak isolasi dipastikan terisolasi dengan baik. Kemudian mesin adsorpsi di jemur di bawah matahari. Dengan naiknya temperatur adsorber maka akan terjadi proses desorpsi yaitu metanol akan menguap dan mengalir ke kondensor ,pada kondensor uap metanol tersebut mencair dan kembali ke evaporator. Tekanan adsorpsi dicatat setiap satu jam sekali. Pengujian ini dilakukan berulang untuk mendapatkan hasil yang maksimal.

- Skema mesin pendingin adsorpsi

Proses desorpsi \pm 9 jam dari pukul 08.00 WIB $-17.00 \mathrm{WIB}$.

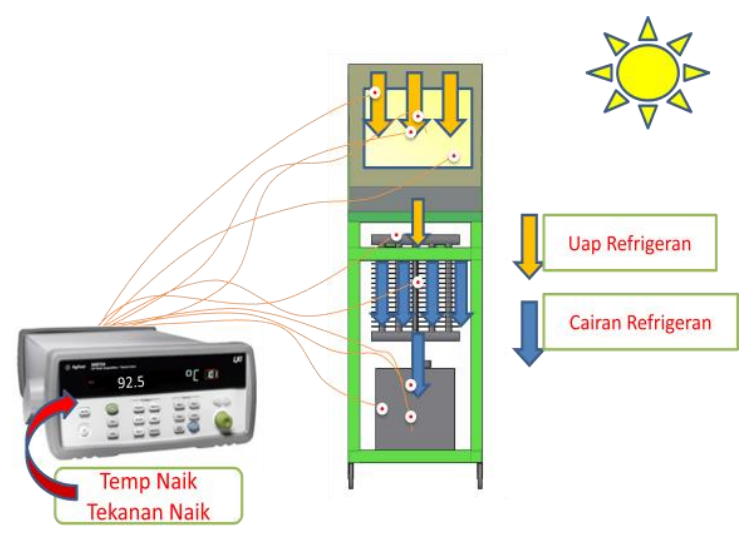

Gambar 1, Proses desorpsi mesin pendingin tenaga surya

Proses adsorpsi berlangsung pada malam hari, temperatur pada proses adsorpsi turun dengan seiring dengan turunnya temperatur lingkungan. 


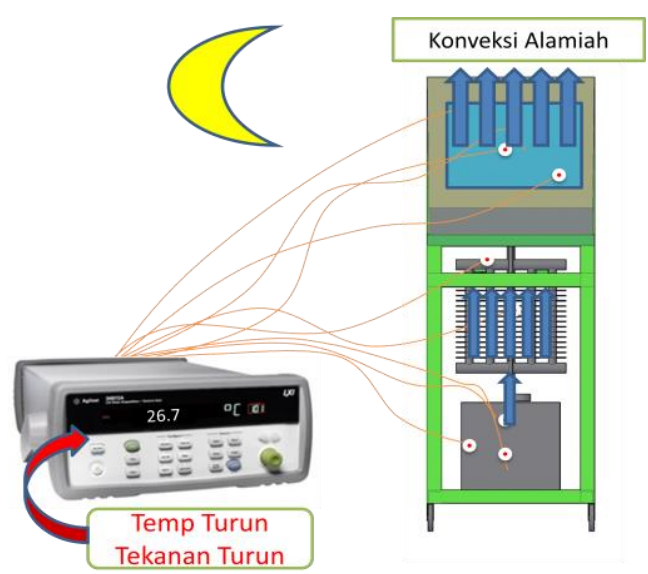

Gambar 2, Proses adsorpsi mesin pendingin tenaga surya

\section{ANALISA DATA}

Data yang diambil dari pengujian adalah data temperatur kolektor, data temperatur kondensor, data temperatur evaporator, dan data tekanan pada kolektor dan evaporator.

\section{Grafik Hasil Pengujian Mesin Adsorpsi}

- $\quad$ Berikut ini ditampilkan grafik data temperatur dari proses pemanasan (desorpsi) sampai proses adsorpsi.

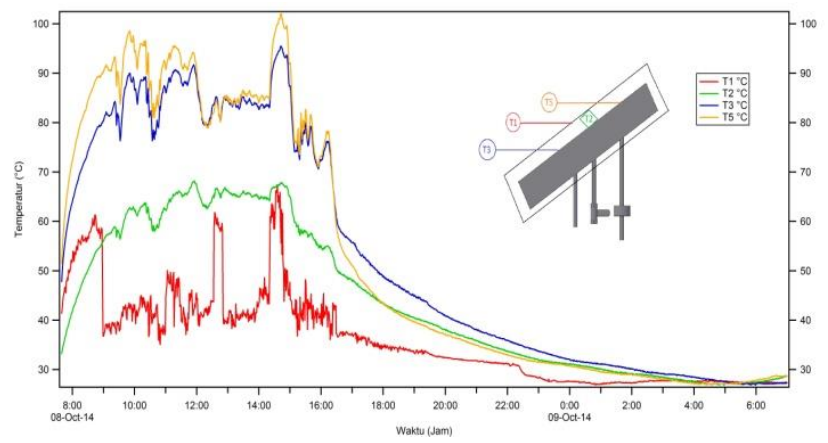

Gambar 3. Grafik temperatur kolektor hari pertama

Gambar 3 merupakan grafik temperatur yang terjadi di kolektor pada hari pertama. Temperatur maksimum terjadi pada pukul 14.41 WIB yaitu $102{ }^{\circ} \mathrm{C}$ pada T5. Temperatur minimum mencapai $27,10{ }^{\circ} \mathrm{C}$ pada $\mathrm{T} 5$ yaitu pada pukul $04.00 \mathrm{Wib}$.

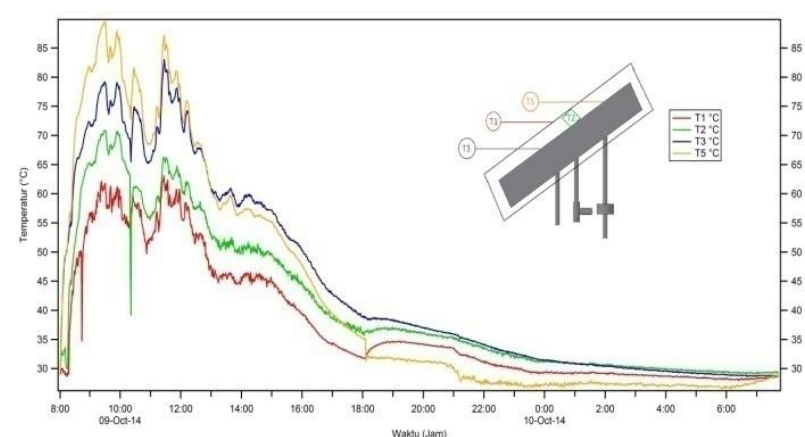

Gambar 4. Grafik temperatur kolektor hari kedua 
Gambar 4 merupakan grafik temperatur yang terjadi di kolektor pada hari kedua. Temperatur maksimum terjadi pada pukul $09.30 \mathrm{Wib}$ yaitu $89,30{ }^{\circ} \mathrm{C}$ pada T5. Temperatur terendah mencapai $26,80^{\circ} \mathrm{C}$ pada T5 yaitu pada pukul 05.20 Wib.

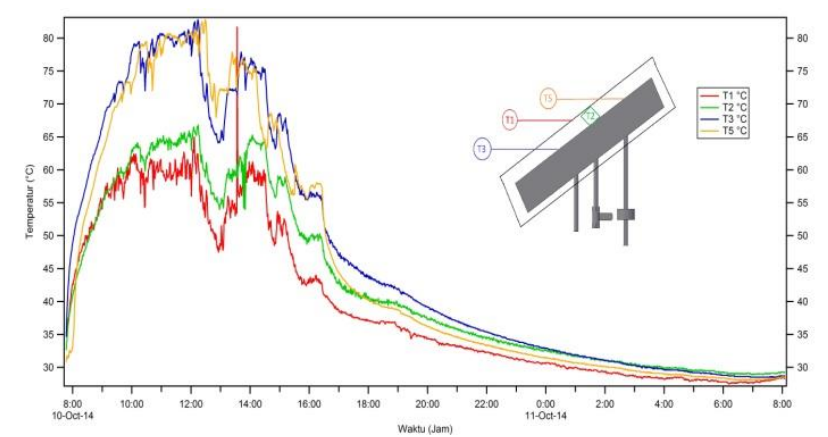

Gambar 5. Grafik temperatur kolektor hari ketiga

Gambar 5 merupakan grafik temperatur yang terjadi di kolektor pada hari ketiga. Temperatur maksimum terjadi pada pukul $12.20 \mathrm{Wib}$ yaitu $80,90{ }^{\circ} \mathrm{C}$ pada Chan T5. Temperatur terendah $28,10{ }^{\circ} \mathrm{C}$ pada $\mathrm{T} 5$ yaitu pada pukul $06.23 \mathrm{Wib}$.

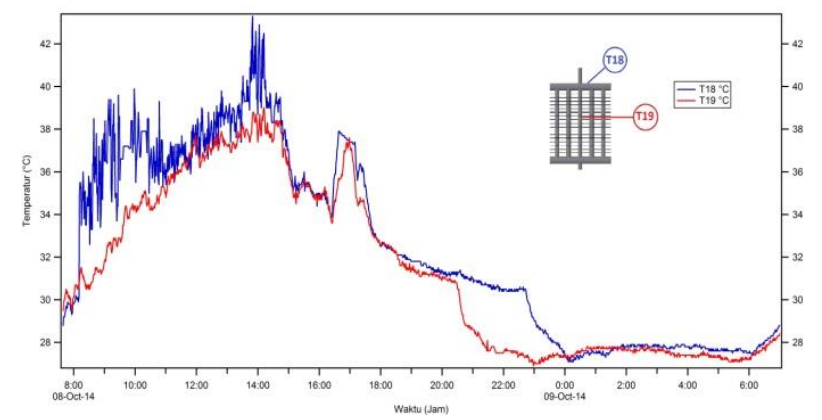

Gambar 6. Grafik temperatur kondensor hari pertama

Gambar 6 merupakan grafik temperatur yang terjadi di kondensor pada hari pertama.

Temperatur paling tinggi pada kondensor pada T18 pukul 13.49 WIB yaitu $43.30^{\circ} \mathrm{C}$.

Sedangkan temperatur paling rendah pada kondensor T19 pada jam 22.58 yaitu $26.90{ }^{\circ} \mathrm{C}$.

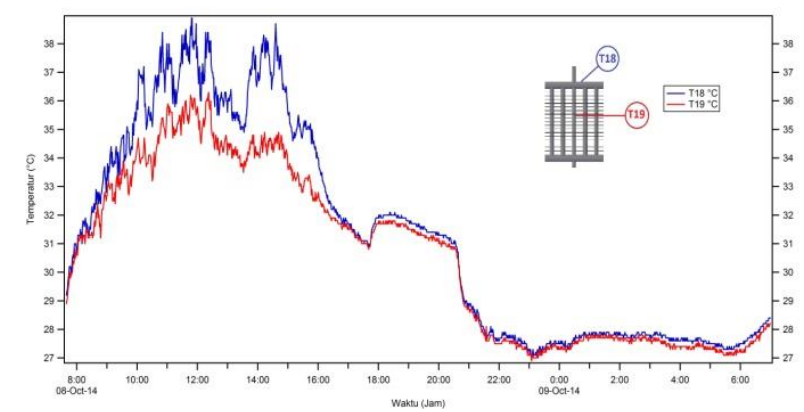

Gambar 7. Grafik temperatur kondensor hari kedua

Gambar 7 merupakan grafik temperatur yang terjadi di kondensor pada hari kedua.Temperatur paling tinggi pada kondensor terjadi pada T18 pada pukul 12.10 WIB yaitu 38,90. Sedangkan temperatur paling rendah pada kondensor terjadi pada T19 pada jam 07.33 WIB yaitu 26,90. 


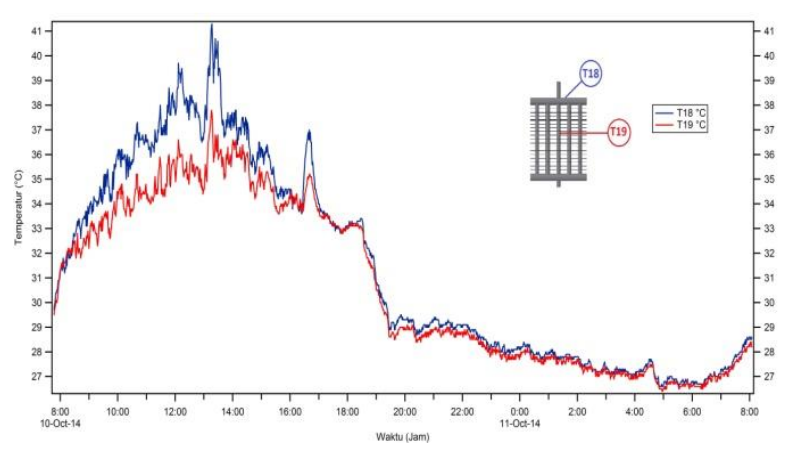

Gambar 8. Grafik temperatur kondensor hari ketiga

Gambar 8 merupakan grafik temperatur yang terjadi di kondensor pada hari ketiga.Temperatur paling tinggi pada kondensor terjadi pada T18 pada pukul 13.16 WIB yaitu $41.30^{\circ} \mathrm{C}$. Temperatur paling rendah pada kondensor terjadi pada T19 pada jam 04.57 yaitu $26.40{ }^{\circ} \mathrm{C}$.

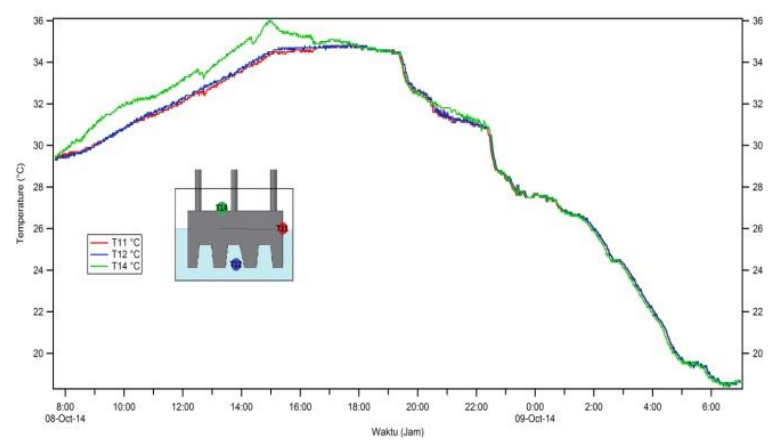

Gambar 9. Grafik temperatur evaporator hari pertama

Gambar 9 merupakan grafik temperatur yang terjadi di evaporator pada hari pertama.Temperatur tertinggi pada evaporator terdapat di T14 pukul 14.54 WIB yaitu $38^{\circ} \mathrm{C}$. Sedangkan temperatur terendah saat proses desorpsi berlangsung pada evaporator yaitu $18,40^{\circ} \mathrm{C}$ yang terdapat pada $\mathrm{T} 11$ pukul $06.35 \mathrm{WIB}$.

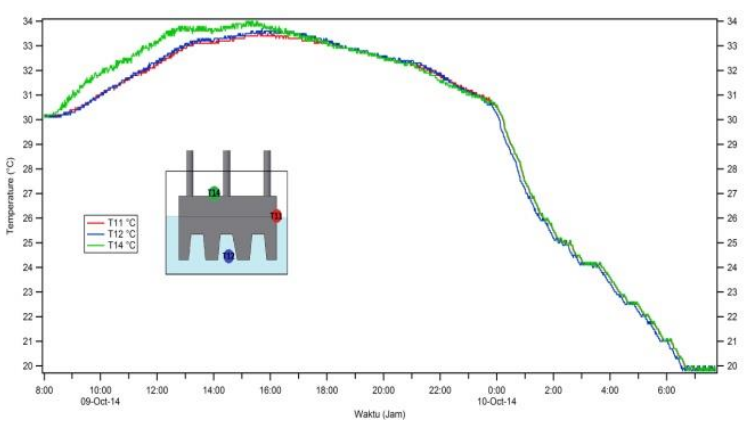

Gambar 10. Grafik temperatur evaporator hari kedua

Gambar 10 merupakan grafik temperatur yang terjadi di evaporator pada hari kedua.Temperatur tertinggi pada evaporator terdapat di T14 pukul 15.08 WIB yaitu $34^{\circ} \mathrm{C}$. Sedangkan temperatur terendah saat proses desorpsi berlangsung pada evaporator yaitu $19,80^{\circ} \mathrm{C}$ yang terdapat pada $\mathrm{T} 11$ pukul $06.41 \mathrm{WIB}$ 


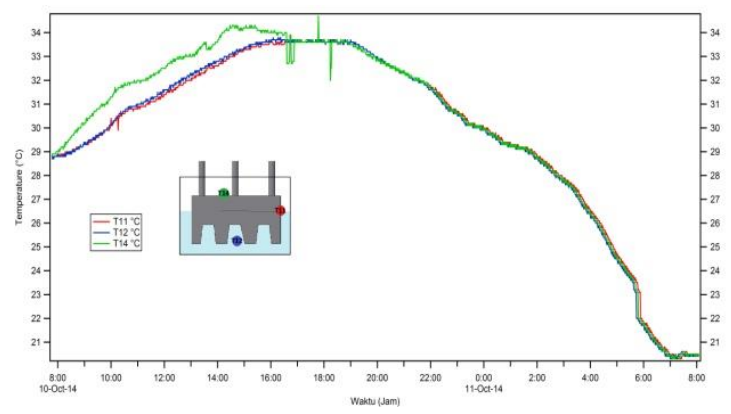

Gambar 11. Grafik temperatur evaporator hari ketiga

Gambar 11 merupakan grafik temperatur yang terjadi di evaporator pada hari ketiga.Temperatur tertinggi pada evaporator terdapat di T14 pukul 17.47 WIB yaitu $34,70^{\circ} \mathrm{C}$. Sedangkan temperatur terendah saat proses desorpsi berlangsung pada evaporator yaitu $20,30^{\circ} \mathrm{C}$ yang terdapat pada $\mathrm{T} 11$ pukul 07.09 WIB.

\section{Perhitungan Hasil Pengujian} Kolektor (Absorber)

Dalam penelitian mesin pendingin tenaga surya Laju perpindahan panas antara kaca kolektor dan pelat penyerap dapat dihitung dengan :

$$
\begin{aligned}
\mathrm{q} & =\frac{\sigma A\left(T_{p}^{4}-T_{c}^{4}\right)}{\frac{1}{\varepsilon_{p}}+\frac{1}{\varepsilon_{c}}-1} \\
& =\frac{5,67 \times 10^{-8} \mathrm{~W} / \mathrm{m}^{2} k^{4}\left(352,88^{4}-308,83^{4}\right)}{\frac{1}{0,98}+\frac{1}{0,84}-1} \\
& =300,16 \mathrm{~W} / \mathrm{m}^{2}
\end{aligned}
$$

$$
\begin{array}{rlr}
\text { Dimana }: & \mathrm{T}_{\mathrm{p}}=\text { Temperatur rata-rata pelat } & \text { kolektor } \\
\mathrm{T}_{\mathrm{c}} & =\text { Temperatur rata- rata pelat } & \text { penutup kaca } \\
\varepsilon_{\mathrm{p}} & =\text { Emisivitas pelat kolektor } & \\
\varepsilon_{\mathrm{c}} & =\text { Emisivitas pelat kaca } &
\end{array}
$$

Koefesien kerugian puncak pada kolektor dengan kemiringan $30^{\circ}$

$$
\begin{aligned}
& \mathrm{Ut}=\left[\frac{N}{\frac{C}{T_{p}}\left(\frac{T_{p-T a}}{N+F}\right) 0,33}+\frac{1}{H_{0}}\right]^{-1}+\frac{\sigma\left(T_{p}+T_{a}\right)\left(\mathrm{T}_{\mathrm{p}}{ }^{2}+\mathrm{T}_{\mathrm{a}}{ }^{2}\right)}{\left[\varepsilon_{p}+0,05 N\left(1-\varepsilon_{p}\right)\right]^{-1}+\left[\frac{2 \mathrm{~N}+\mathrm{F}-1}{\varepsilon \mathrm{g}}\right]-\mathrm{N}} \\
& \mathrm{C}=250\left[1-0,0044\left(\beta-90^{\circ}\right)\right] \\
& \mathrm{C}=250[1-0,0044(30-90)]=316 \\
& \mathrm{H}_{0}=5,7+3,8 \mathrm{~V} \mathrm{~W} / \mathrm{m}^{2} . \mathrm{K} \\
& =5,7+3,8 \times 4 \mathrm{~W} / \mathrm{m}^{2} \cdot \mathrm{K} \\
& =20,9 \\
& \mathrm{~F}=\left(1-0,04 \mathrm{~h}_{\mathrm{o}}+0,0005 \mathrm{~h}_{\mathrm{o}}^{2}\right)(1+0,091 \mathrm{~N}) \\
& \mathrm{F}=(1-0,04(20,9))+0,0005(20,9)^{2}(1+0,091(2)) \\
& =0,42 \\
& {\left[\frac{2}{\frac{316}{352,88}\left(\frac{352,88-308,83}{2+0,42}\right) 0,33}+\frac{1}{20,9}\right]^{-1}+\frac{5,67 \times 10^{-8}(352,88+308,83)\left(352,88^{2}+308,83^{2}\right)}{[0,98+0,05(2)(1-0,98)]^{-1}+\left[\frac{2(2)+0,42-1}{0,84}\right]-2}}
\end{aligned}
$$




$$
\begin{aligned}
\mathrm{Ut} & =2,382+2.768 \\
& =5.15
\end{aligned}
$$

Maka, koefesien kerugian puncak adalah $5.15 \mathrm{~W} / \mathrm{m}^{2} \mathrm{~K}$

Laju perpindahan kalor secara konduksi pada adsorber dapat ditentukan dengan :

$$
q_{k o n d u k s i}=-k A \frac{d t}{d x} \quad w(w a t t)
$$

Luas pelat $(A)=0,5 \mathrm{~m} \times 0,5 \mathrm{~m}=0,25 \mathrm{~m}^{2}$

Tebal pelat $(\partial x)$ adalah $1 \times 10^{-3} \mathrm{~m}$

Nilai k dapat dicari dari tabel sifat-sifat logam.

$$
\begin{aligned}
T & =\frac{\mathrm{T}_{1}+\mathrm{T}_{2}}{2} \\
T & =\frac{79.88+35.83}{2}=57,85+273 \\
T & =330,85 \mathrm{k} \\
k & =15,1-0,30(15,1-17,3) \\
& =15,76^{\mathrm{W}} / \mathrm{m}^{2} \\
q_{\text {konduksi }} & =15,76 \times 0,25\left(\frac{352,88-308,83}{1 \times 10^{-3}}\right) \\
& =173.577 \mathrm{~W} / \mathrm{m}^{2}
\end{aligned}
$$

Laju perpindahan kalor secara konveksi pada adsorber dapat ditentukan dengan :

$\mathrm{Q}_{\text {konveksi }}=\mathrm{hA}(\mathrm{Tw}-\mathrm{Ts}) \mathrm{Watt}$

$$
\begin{aligned}
& =10^{\mathrm{W}} / \mathrm{m}^{2} \times 0.25 \mathrm{~m}^{2}(352,88-308,83) \\
& =110,125^{\mathrm{W}} / \mathrm{m}^{2}
\end{aligned}
$$

Laju perpindahan kalor secara radiasi pada adsorber dapat ditentukan dengan

$$
\begin{aligned}
& \mathrm{q}=\sigma \mathrm{A}\left(\mathrm{T}_{1}{ }^{4}-\mathrm{T}_{2}{ }^{4}\right) \\
& \begin{aligned}
\mathrm{T}_{\text {langit }}= & 0.0552\left(\mathrm{Ta}^{3} / 2\right) \\
= & 0.0552\left(308 \cdot 83^{3 / 2}\right) \\
= & 299,58 \mathrm{k}
\end{aligned} \\
& \mathrm{q}=0,98 \cdot\left(5,67 \times 10^{-8}\right) \cdot 0,25 .\left(352,88^{4}-299,58^{4}\right) \\
& \mathrm{q}=103,51 \mathrm{~W} / \mathrm{m}^{2}
\end{aligned}
$$

Sehingga, energi panas total yang diserap oleh adsorber adalah :

$\mathrm{q}_{\mathrm{T}}=\alpha \mathrm{G}_{\text {solar }}-\mathrm{q}_{\text {konduksi }}-\mathrm{q}_{\text {konveksi }}-\mathrm{q}_{\text {radiasi }}$

$$
=0,98 \times 309.432,1-173.577-110,25-103,51
$$

$\mathrm{q}_{\mathrm{T}}=129.880,2 \mathrm{~W} / \mathrm{m}^{2}$

Maka, panas netto yang dibangkitkan adsorber adalah $=129.880,2 \mathrm{~W} / \mathrm{m}^{2}$ 
Effisiensi kolektor adalah

$$
\begin{aligned}
(\eta) & =\frac{q_{T}}{q_{\text {solar }}} \\
& =\frac{129.880,2}{309.432,1} \\
& =0,41
\end{aligned}
$$

\section{Kondensor}

Persamaan-persamaan yang berlaku pada perpindahan panas ini adalah sebagai berikut:

Tebal lapisan batas

$$
\delta=3,936 \mathrm{~L}\left(\frac{0,952+\operatorname{Pr}}{\operatorname{Pr}^{2}}\right)^{0,25} \times \mathrm{Gr}_{\mathrm{L}}^{-0,25}
$$

dimana : Pr adalah bilangan Prandtl untuk udara yaitu 0,72.

Menghitung Bilangan Grasholf dengan cara :

$$
\begin{aligned}
G r_{L}= & \frac{1,165^{2} \times 9,81 \times 10^{-3}(50,2-31,96) \times 0,1^{3}}{\left(1,86 \times 10^{-5}\right)^{2}} \\
& =7,01972 \times 10^{5}
\end{aligned}
$$

Menghitung tebal lapisan batas

$$
\begin{aligned}
\delta=3,936 \mathrm{~L}\left(\frac{0,952+\operatorname{Pr}}{\operatorname{Pr}^{2}}\right)^{0,25} \times \mathrm{Gr}_{\mathrm{L}}^{-0,25} \\
=3,936 \times 0,1\left(\frac{0,952+0,72}{0,72^{2}}\right)^{0,25} \times\left(7,01972 \times 10^{5}\right)^{-0,25}
\end{aligned}
$$

$=0,046298 \mathrm{~cm}$

$2 \delta=2 \times 0,046298=0,092596<$ jarak kedua plat. Maka aliran yang terjadi masih berkembang Menghitung perpindahan panas pada satu permukaan plat vertikal, dengan menggunakan persamaan :

$$
\begin{aligned}
q^{\prime} & =\bar{h} A\left(T_{S}-T_{\infty}\right)=\frac{k}{L} 0,549 R a^{0,25} \\
q^{\prime} & =\frac{0,026}{0,1} \times 0,549 \times\left(7,01972 \times 10^{5} \times 0,72\right)^{0,25} \\
& =3.8 \mathrm{~W} / \mathrm{m}
\end{aligned}
$$

Jumlah plat pada kondensor ada 17 buah, setiap plat mempunyai 2 permukaan, panjang tiap plat $0,4 \mathrm{~m}$ maka laju perpindahan panas total dari kondensor adalah :

$$
Q_{\text {total }}=3.8 \times 17 \times 2 \times 0,4=51.68 \mathrm{~W}
$$

Menghitung laju aliran metanol pada kondensor.

$$
\begin{aligned}
& q_{u}=160,39 \mathrm{~W} / \mathrm{m}^{2} \\
& q_{u} A=\dot{m}_{c p}\left(T_{i}-T_{o}\right) \\
& \dot{m}=\frac{\mathrm{q}_{\mathrm{u}} A}{\mathrm{C}_{\mathrm{p}}\left(\mathrm{T}_{\mathrm{i}}-\mathrm{T}_{\mathrm{o}}\right)} \\
& =\frac{160,39 \frac{\mathrm{W}}{\mathrm{m} 2}\left(0,795 \mathrm{~m}^{2}\right)}{0,005 \frac{\mathrm{kj}}{\mathrm{kg} \mathrm{k}}(311,92 \mathrm{~K}-297,3 \mathrm{~K})} \\
& =1,74 \frac{\mathrm{Kg}}{j a m}=0,000483 \frac{\mathrm{Kg}}{\mathrm{s}}
\end{aligned}
$$

Maka, laju aliran methanol pada kondensor adalah $0,000483 \frac{\mathrm{Kg}}{\mathrm{s}}$ 


\section{Evaporator}

Untuk menghitung kalor yang diserap oleh pelat evaporator, digunakan persamaan panas sensibel.

$$
Q_{s}=\dot{m} \cdot \mathrm{C}_{\mathrm{p}} \cdot \Delta \mathrm{t}
$$

Kapasitas kalor spesifik sensibel plat evaporator $480 \frac{\mathrm{j}}{\mathrm{kg} \mathrm{k}}$

$m_{e v}=$ massa plat evaporator $2,62 \mathrm{~kg}$

$Q_{\text {sev }}=$ kalor sensibel plat evaporator

$\Delta T \quad=$ Perubahan suhu $(\mathrm{k})$

$=$ Perubahan temperaur diambil dari temperatur rata rata sore hari sampai temperatur terendah plat evaporator pagi hari.

Sehingga untuk pengujian diperoleh besar perubahan temperatur sebagai berikut:

$$
\Delta T=27,12^{\circ} \mathrm{C}+273=300,12 \mathrm{~K}
$$

Sehingga kalor sensibel plat evaporator

$$
Q_{\text {sev }}=2,62 \mathrm{~kg} \times 480 \frac{\mathrm{j}}{\mathrm{kg} \mathrm{k}} \times 300,12 \mathrm{~K}=377.430,9 \mathrm{j}=377,430 \mathrm{kj}
$$

Untuk menghitung kalor yang dibutuhkan metanol dalam proses penguapan pada saat proses adsorpsi digunakan persamaan kalor laten.

$Q_{L}=l e . m$

$Q_{L}=$ kalor laten metanol (j)

$l e=$ kapasitas kalor spesifik laten $\left(\frac{\mathrm{J}}{\mathrm{kg}}\right)$

$m=$ massa metanol $(\mathrm{kg})$

$V_{\text {metanol }}=4 \mathrm{~L}$

$$
=4 \times 10^{-3} \mathrm{~m}^{3}
$$

$\rho_{\text {metanol }}=787 \mathrm{~kg} / \mathrm{m}^{3}$

Dari data di atas massa metanol adalah

$$
\begin{aligned}
m_{\text {metanol }} & =V_{\text {metanol }} x \rho_{\text {metanol }} \\
& =4 \times 10^{-3} \times 787 \\
& =3,14 \mathrm{~kg} \\
L_{\text {e metanol }} & =1100 \mathrm{~kJ} / \mathrm{kg}
\end{aligned}
$$

Sehingga dapat dihitung kalor laten penguapan metanol dapat dihitung dengan persamaan berikut ini.

$$
\begin{aligned}
& Q_{L}=L_{e} \cdot m \\
& Q_{L}=1100 \mathrm{~kJ} / \mathrm{kg} \times 3,14 \mathrm{~kg} \\
& Q_{L}=3454 \mathrm{Kj}
\end{aligned}
$$

Analisa kalor pada air

Pada penelitian ini,media yang didinginkan adalah air, dalam hal ini kalor yang dihitung adalah panas sensibel dari air, dengan menggunakan persamaan :

$Q_{s}=\dot{m} \cdot \mathrm{C}_{\mathrm{p}} \cdot \Delta \mathrm{t}$

Dimana

$Q_{s}=$ kalor sensibel air (j) 
$m=$ massa air $(\mathrm{kg})$

Massa air $1,942 \mathrm{~kg}$

$\mathrm{C}_{\mathrm{p}}=$ kapasitas kalor spesifik sensibel air $\frac{\mathrm{j}}{\mathrm{kg} \cdot \mathrm{k}}$

$\Delta T \quad=$ Perubahan suhu $(\mathrm{k})$

$=$ Perubahan temperaur diambildari temperatur rata rata sore hari sampai

temperatur terendah plat evaporator pagi hari.

Kesetimbangan energi

Proses terjadinya pendinginan pada sistem ini dipengaruhi oleh kalor yang diperlukan metanol untuk menguap, dimana panas yang diserap metanol harus lebih besar dengan kalor yang dikeluarkan oleh plat evaporator dan air.

Penyerapan panas oleh metanol

- Volume $=2$ liter $\left(4 \times 10^{-3}\right)$

- Massa jenis $\left(30^{\circ}\right)=787 \mathrm{~kg} / \mathrm{m}^{3}$

- Massa metanol $=787 \mathrm{~kg} / \mathrm{m}^{3} \times 1 \times 10^{-3} \mathrm{~m}^{3}=3,14 \mathrm{~kg}$

- Panas laten penguapan $=1100 \mathrm{~kJ} / \mathrm{kg}$

- Total panas yang diserap metanol selama menguap :

$=0,787 \mathrm{~kg} \times 1100 \mathrm{~kJ} / \mathrm{kg}=865,7,61 \mathrm{Kj}$

Penggunaan panas penyerapan

- Volume $=2$ liter $\left(2 \times 10^{-3} \mathrm{~m}^{3}\right)$

- Massa jenis air $\left(30^{\circ} \mathrm{C}\right)=791 \mathrm{~kg} / \mathrm{m}^{3}$

- Massa air $=1 \times 10^{-3} \mathrm{~m}^{3}$ x $1942 \mathrm{~kg}=1,942 \mathrm{~kg} / \mathrm{m}^{3}$

- Panas jenis air pada $30{ }^{\circ} \mathrm{C}=4,179 \mathrm{~kJ} / \mathrm{kg}{ }^{\circ} \mathrm{C}$

- Panas Pembekuan $=334 \mathrm{Kj} / \mathrm{Kg}$

Menurunkan suhu air dari $30{ }^{\circ} \mathrm{C}$ menjadi $0^{\circ} \mathrm{C}$

$Q_{\text {air }}=\dot{m} \cdot \mathrm{C}_{\mathrm{p}} \cdot \Delta \mathrm{t}$

$=1,942 \mathrm{~kg} \times 4,179 \frac{\mathrm{kJ}}{\mathrm{kg}^{\circ} \mathrm{C}} \times 27,17^{\circ} \mathrm{C}$

$=220,5 \mathrm{kj}$

Membekukan air pada $0{ }^{\circ} \mathrm{C}$

$$
\begin{aligned}
\mathrm{Q} & =\mathrm{m} \times 1 \\
& =1,942 \mathrm{~kg} \times 334 \frac{\mathrm{Kj}}{\mathrm{Kg}} \\
& =648,62 \mathrm{Kj}
\end{aligned}
$$

Menurunkan suhu evaporator dari $30^{\circ} \mathrm{C}$ menjadi $0^{\circ} \mathrm{C}$

Hari pertama pengujian 


$$
\begin{aligned}
Q_{e v} & =\dot{m} \cdot \mathrm{C}_{\mathrm{p}} \cdot \Delta \mathrm{t} \\
& =2,62 \mathrm{~kg} \times 0,48 \frac{K j}{\mathrm{~kg}^{\circ} \mathrm{k}} \times 300,12 \mathrm{~K} \\
& =377,43 \mathrm{Kj}
\end{aligned}
$$

Total energi panas yang digunakan untuk mengubah air menjadi es $377.43 \mathrm{Kj}+220,5 \mathrm{Kj}=597,93 \mathrm{Kj}$

\section{KESIMPULAN DAN SARAN \\ Kesimpulan}

1. Temperatur maksimum pada kolektor di hari pertama pengujian adalah $102{ }^{\circ} \mathrm{C}$, pada hari kedua $89.30{ }^{\circ} \mathrm{C}$, dan pada hari ketiga $80.90{ }^{\circ} \mathrm{C}$.

2. Temperatur maksimum air di hari pertama pengujian adalah $38^{\circ} \mathrm{C}$ dan temperatur minimum $18,40{ }^{\circ} \mathrm{C}$, pada hari kedua temperatur maksimum $33,70^{\circ} \mathrm{C}$ dan temperatur minimum $19,80{ }^{\circ} \mathrm{C}$, pada hari ketiga temperatur maksimum $33,70{ }^{\circ} \mathrm{C}$ dan temperatur minimum $20,30^{\circ} \mathrm{C}$.

3. Efisiensi kolektor tertinggi pada hasil pembahasan adalah $52 \%$

\section{Saran}

Untuk kelanjutan dan pengembangan penelitian ini ke depannya, penulis menyarankan agar penelitian berikut hendaknya memperhatikan beberap hal sebagai berikut :

1. Kevakuman sistem, dalam hal ini kebocoran dan rendahnya kevakuman pada sistem agar lebih diperhatikan karena proses adsorpsi hanya bisa terjadi jika evaporator dalam keadaan vakum.

2. Untuk menghindari data error, sebelum pengujian hendaknya mengecek seluruh termokopel yang akan digunakan.

\section{DAFTAR PUSTAKA}

[1] Damanik, Masrin. 2011. Kajian Ekprimental Untuk Mesin Pendingin Siklus Adsorpsi yang Digerakkan Energi Surya. USU

[2] Ambarita, Himsar. 2012. Buku Kuliah teknik Pendingin \& Pengkondisian Udara. Medan

[3] L.W. Wang, dkk. 2003. Study of the Performance of actived carbon-Methanol adsorption system concerning heat and mass transfer. Journal of Applied Thermal Engineering. China

[4] Incropera, F.P., DeWit, Bergan, Lavine. 2006. Fundamentals of Heat and Mass Transfer, $6^{\text {th }}$ edition. 